\title{
A NONINVASIVE TECHNIQUE FOR SAMPLING FOOD AVAILABILITY FOR FOLIAGE-GLEANING BIRDS
}

JOSEPH J. FONTAINE, U.S. Geological Survey Nebraska Cooperative Fish and Wildlife Research Unit, and the School of Natural Resources, The University of Nebraska, Lincoln, Nebraska 68583; jfontaine2@unl.edu

KARIE L. DECKER, Arizona Cooperative Fish and Wildlife Research Unit, and the School of Natural Resources and the Environment, University of Arizona, Tucson, Arizona 85721

ABSTRACT: We describe a noninvasive modification to the technique of branchclipping for sampling arthropods and evaluate its efficacy for studying food resources for a foliage-gleaning warbler breeding in the sky islands of southern Arizona. In the foliage-area method, arthropod abundance is measured on individual branches, and search area is controlled for by estimating surface area with a shadowed grid, analogous to canopy cover being estimated with a densiometer. Our technique enables repeated sampling of the same branch, which can limit sampling error and facilitates detailed studies of phenology across seasons and over multiple years. Overall it required less effort than traditional approaches, but because of the logistical challenges associated with sampling tree canopies, it is best suited for studies of species that forage relatively low to the ground. The foliage-area method does not alter the habitat, making it ideally suited for studies in protected areas, when foliage is limiting, or for work with food crops or endangered plant species.

Assessing the availability and distribution of food resources is essential to addressing a variety of questions in ecology (e.g., Morrison et al. 1990). For insectivorous species, however, the cost and time constraints associated with sampling arthropods often limit sampling effort (Morris 1960, Southwood 1980, Smith and Rotenberry 1990, Poulin and Lefebvre 1997). Branch-clipping is gaining favor as an easy and effective method for sampling arthropod communities. In this technique, researchers estimate the density of arthropods on a plant by measuring the dry mass of clipped branches upon which the arthropods are counted (Johnson 2000, Vitz and Rodewald 2006, McGrath et al. 2009, Decker et al. 2012). Unfortunately, because it is destructive to the sampled plant, branch-clipping is precluded when foliage is limited (e.g., in desert riparian corridors), on food crops or endangered plants, or when temporal changes are being assessed, as in studies of plant/arthropod phenology, herbivory, or arthropod depletion. Alternative approaches to estimating arthropod density, such as counting the number of individual arthropods per leaf (e.g., Holmes et al. 1979, Holmes and Schultz 1988), are equally limited when a study addresses phenology or when plant species with different leaf sizes are being compared, as the number of leaves may not reflect the availability of habitat for arthropods. Here we describe and evaluate a novel sampling technique, the foliagearea method, which is based on the relationship between the number of arthropods counted and the estimated area of foliage and overcomes some limitations of sampling. Specifically, we evaluate and compare the foliagearea method to the branch-clipping method for measuring differences in food resources among substrates and across the breeding season for the 
Red-faced Warbler (Cardellina rubrifrons). We contrast the limitations and advantages of the foliage-area protocol in comparison to the branch-clipping method, and discuss its application.

\section{METHODS}

From April to July of 2008, we sampled arthropods on four 16- to 20-ha study plots in a high-elevation $(2300-2700 \mathrm{~m})$ mixed-conifer forest in the Coronado National Forest, Santa Catalina Mountains, Pima County, Arizona $\left(32.43^{\circ} \mathrm{N}, 110.76^{\circ} \mathrm{W}\right)$. Sampling was limited to larvae of Lepidoptera found on the outermost 25-45 cm of White Fir (Abies concolor) and Big-tooth Maple (Acer grandidentatum) branches located 0.25-2.5 m off the ground because Red-faced Warblers regularly forage in the lower branches of these trees, and approximately 80\% of their diet during the breeding season is Lepidoptera (Martin and Barber 1995, K. Decker unpubl. data).

To estimate the density of larvae we first visually inspected and tallied the number of larvae on the top and underside of all leaves, flowers, and stems of the sampled branch, being careful not to disrupt the arthropod community. Visual inspection has limitations (Cooper and Whitmore 1990) but is appropriate when arthropods are sessile, not highly cryptic, and therefore easily detected (Moir et al. 2005). If necessary, however, alternative sampling techniques (e.g., enclosing the branch in a container and shaking or gassing it) are adaptable to the foliage-area method. Next we estimated the surface area of each sampled branch by placing the branch (while attached to the tree) on a grid (Figure 1) and counting the number of squares covered

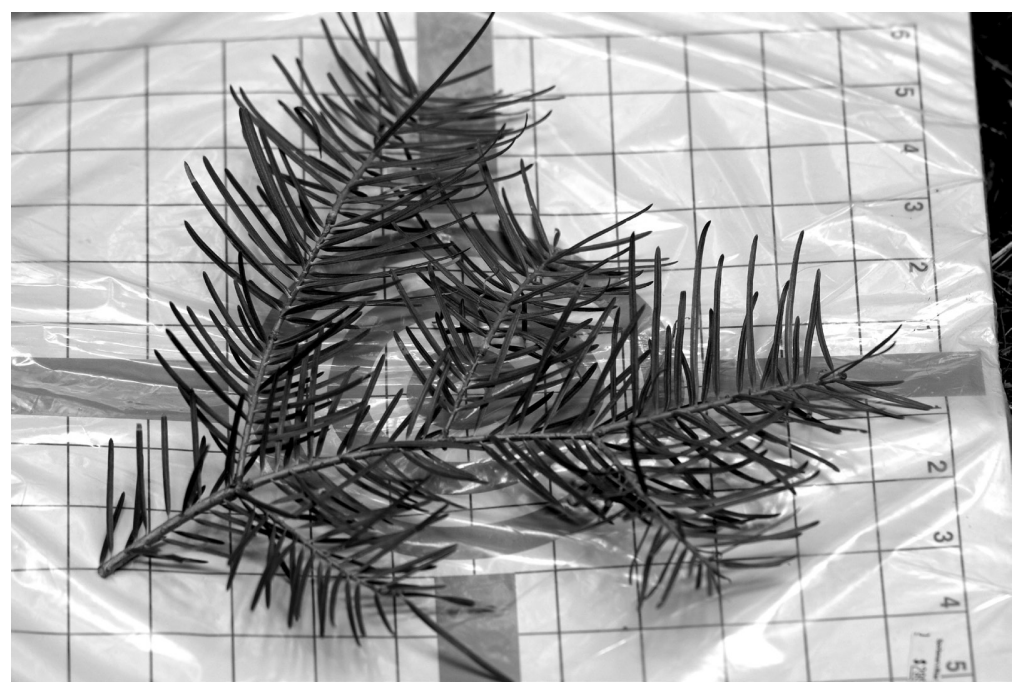

Figure 1. The foliage-area method relies on an estimation of branch area to account for search effort. A branch is placed on a gridded piece of paper, and the number (or percentage) of covered squares is recorded to estimate area. 
by any part of the branch, be it stem, leaf, or flower, in a manner similar to estimating canopy cover with a densiometer. Although gridded paper can be made, we used an inexpensive (\$3/dozen) paper target, which we laminated to protect it against the elements. The grid consisted of a series of 144 squares, each $2.5 \mathrm{~cm} \times 2.5 \mathrm{~cm}$ (totaling $900 \mathrm{~cm}^{2}$ per grid), which was large enough for our sampling, but larger grids could be constructed. Note that the size of the grid squares may influence the precision of the estimates of area, so smaller grid squares may be necessary to distinguish small differences among substrates. After measuring the area of each branch, we cut and removed the branch from the tree, placed it in a paper bag, and stored it in a cool dry location until the completion of the field season. All branches were dried at $40^{\circ} \mathrm{C}$ for approximately 48 hours and weighed with a digital scale (accurate to $0.001 \mathrm{~g}$ ).

We sampled 40 branches from Big-tooth Maple, mean mass $3.91 \mathrm{~g} \mathrm{( \pm}$ SD 1.79) and area $346.25 \mathrm{~cm}^{2}( \pm 145.3)$, and 41 branches from White Fir, mean mass $14.08 \mathrm{~g}( \pm 5.54)$ and area $457.32 \mathrm{~cm}^{2}( \pm 139.91)$. Since the numerator in both calculations of density is the same (number of arthropods counted), we compared the methods on the basis of the denominators, estimated area and dry mass of each branch. After transforming the data by the natural logarithm to meet assumptions of normality, we examined the relationship between area and mass by means of two two-tailed Pearson correlation tests, one for each tree species. Using the Fisher $r$-to- $z$ transformation, we then compared the correlations to see if the relationship between mass and area differed by tree species. We also examined how the density of larvae on the two species of trees differed with a Wilcoxon-Mann-Whitney two-sample rank-sum test. Finally, we examined seasonal patterns by averaging counts of larvae for each week and assessing changes by linear regression and a Student's t-test to compare the lines' slopes.

\section{RESULTS}

Branch area was significantly correlated with dry mass for both tree species (Figure 2; maple: $r_{39}=0.887, P<0.001$; fir: $r_{40}=0.991, P<$ $0.001)$, but the area-mass curves did differ $(Z=-5.52, P<0.001)$. We found no difference between the two species in density of larvae (Figure 3; branch-clipping: Mann-Whitney $U=811.0, n_{1}+n_{2}=81, P=0.870$; foliage-area: Mann-Whitney $\left.U=817.0, n_{1}+n_{2}=81, P=0.956\right)$. Both techniques showed a similar $\left(t_{5}=0.541, P>0.25\right)$ although insignificant seasonal decline in the density of larvae (Figure 3 ; branch-clipping: $t_{5}=$ $-0.736, P=0.502$; foliage-area: $\left.t_{5}=1.048, P=0.354\right)$.

\section{DISCUSSION}

Estimating food resources for insectivorous birds requires balancing the desire for ample high-quality data with the need to reduce the cost of sampling and inadvertent damage to the system being studied. With practice, we estimated the abundance of lepidopteran larvae on a branch and the branch's surface area within 2-3 minutes by the foliage-area method, obtaining results similar to those yielded by the traditional method of measuring dry leaf mass 


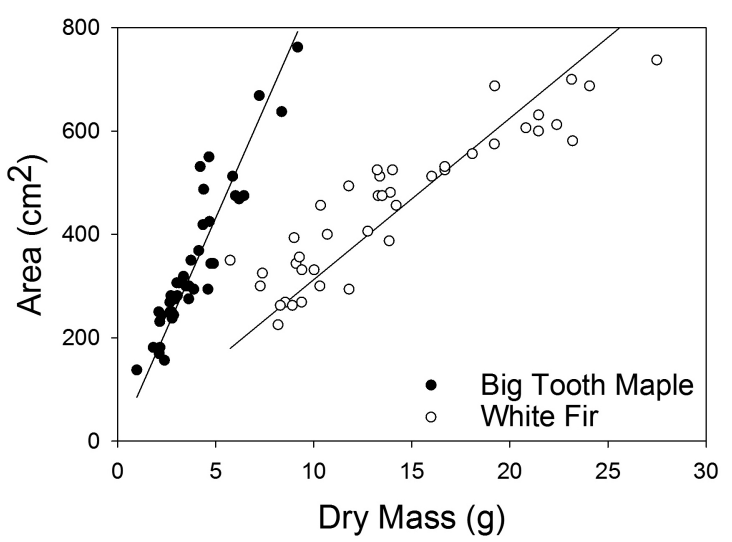

Figure 2. Estimating food resources for birds requires calibrating arthropod abundance against available habitat. Results of the foliage-area method of calibration are strongly correlated with those of the traditional approach based on estimating arthropod abundance from the dry mass of a clipped branch. Data represent the two species of trees (•, Big-tooth Maple; $\bigcirc$, White Fir) in which Red-faced Warblers prefer to forage.

(Figure 3). In contrast, estimates from the branch-clipping technique were not available until after the field season when drying of branches was completed. Measuring the mass of a branch in the field saves time (e.g., Johnson 2000), but water content, a significant component of branch mass, varies with a tree's age, phenology, and resource availability (Field and Mooney 1983, Larcher 2001), introducing considerable error into estimates. Measuring area, not mass, is a more intuitive means of measuring arthropod habitat and has the added benefit of not altering the vegetation.

We observed a strong correlation between branch area and dry mass (Figure 2), but the slopes for the two tree species differed. The difference in the area-mass relationships may indicate that the foliage-area method should not be used to compare estimates of arthropod density on different tree species that differ in form of branches and leaves, or it may indicate that branch mass is not an ideal measure of the availability of arthropod habitat (see below). The use of a grid has advantages over visual estimations, but precision is sensitive to grid size (Cooperrider et al. 1986, Bookhout 1994). Although a leaf-area meter (e.g., O'Neal et al. 2002) or computer analysis of digital photographs (e.g., Meyer and Davison 1987, Jorgensen et al. 2013) yield more precise results, these techniques are also more costly and time consuming.

Obviously, any approach that estimates area fails to account for vertical structure. Although we had no difficulty getting samples to lay flat, even of White Fir, which has a relatively whorled leaf structure, we suggest that there are means to overcome complex branch structures. When a branch is flexible, we found that compressing it against the grid with a clear sheet of plastic successfully incorporated the vertical component of the branch into the area estimate. This approach proved particularly useful when we test- 


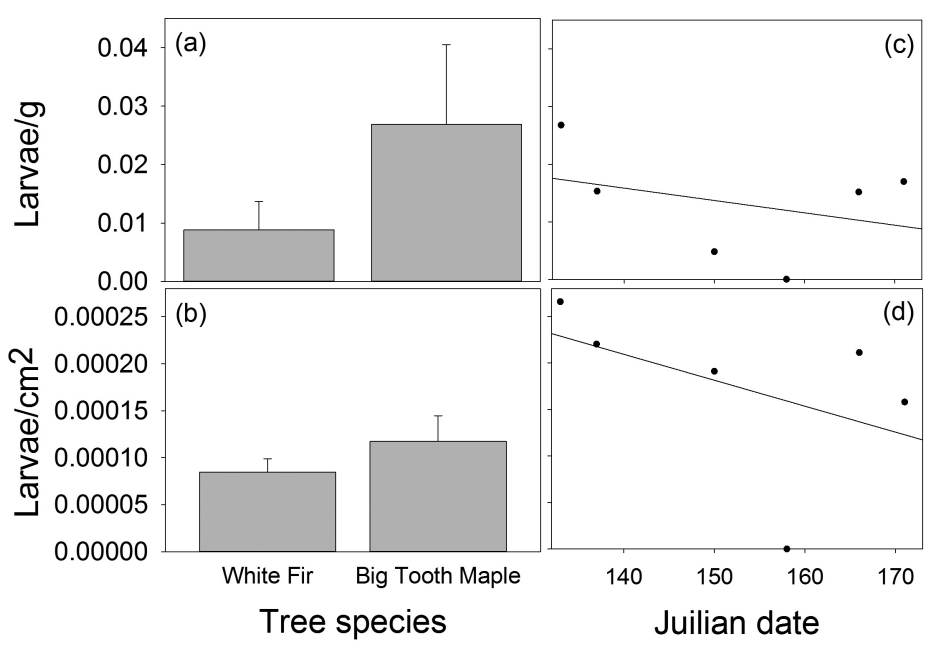

Figure 3. Comparison of estimates of density of lepidopteran larvae by species of tree $(\mathrm{a}, \mathrm{b}$; mean $\pm \mathrm{SD}$ ) and through the season $(\mathrm{c}, \mathrm{d}$; mean and linear regression) by the foliage-area method we describe and by estimating arthropod abundance from the dry mass of a clipped branch. The patterns of results from the two techniques did not differ.

sampled long-needled pines, but it carries the risk of damaging the plant and arthropods. Another approach is to use the grid to measure both horizontal and vertical area as an additive estimate of the total area. While this approach is effective, it likely limits comparisons to a single tree species because differences between species in the structure of branches can lead to error.

We believe that the tree-specific area-mass relationship we found is related to differences in the proportion of leaf and stem on a given branch, not to sampling error. This finding is important because while the majority of arthropod habitat on a branch is often leaf, because of the difference between stems and leaves in density, the majority of a branch's mass is almost always stem. If mass rather than surface area of a branch is used as an index, the relative density of arthropods may be both overestimated (i.e., small stem, large or many leaves) and underestimated (i.e., large stem, small or few leaves), making comparisons between tree species or even samples difficult. This supposition is supported by our data, which suggest that the relative difference in density of larvae between the White Fir and Big-tooth Maple, the former being dominated by stem, the latter by leaves, is greater when the density of larvae is estimated by mass rather than by area (Figure 3). In practice this may have little effect on estimates when branches with similar structure are compared, but the difference may be important in a study encompassing multiple plant species or plants undergoing changes in phenology. Moreover, most food studies assess birds' foraging behavior (e.g., Johnson 2000, McGrath et al. 2009), and while it may be reasonable to suspect a relationship between branch mass and arthropod abundance, the linkage to foraging strategy is more dubious, as studies of predator-prey 
interactions refer to the area searched, not the mass (e.g., Andersson 1981). Counting arthropods per leaf (e.g., Holmes et al. 1979) may overcome some of these problems, but not in studies of phenology where leaf area, and thus arthropod habitat and the area a bird searches, change over time.

Like other methods of sampling, the foliage-area method has limitations (see Cooper and Whitmore 1990). Most significantly, it is important to identify the tree species and foraging locations appropriate to the birds being studied to ensure samples are representative (Cooper and Whitmore 1990). Like the branch-clipping method, the foliage-area method has limited applicability for aerial foragers and for arthropods that are prone to escape or fall from branches (Johnson 2000). Without the use of a ladder, a logistical challenge, the foliage-area method is restricted to heights $<2.5 \mathrm{~m}$, which is about half the height available to researchers using an extendable tree pruner to collect branch samples (generally $<6 \mathrm{~m}$ ). Visually counting rather than collecting arthropods has limitations if identifying the prey species is important, or if the prey vary in size, but this can be overcome by using a portable reference collection and classifying prey by body size. Finally, highly cryptic arthropods may prove challenging, particularly when a branch of complex structure is sampled. In our case, we were successful in finding the small green lepidopteran larvae that dominate the Red-faced Warbler's diet (Martin and Barber 1995). In some cases, however, shaking or gassing of the branch may prove necessary.

The foliage-area method overcomes some of the limitations of the branch-clipping method, uses a more intuitive measure of sampling effort, and proved effective for sampling larvae of Lepidoptera. Still, estimating food resources for insectivorous birds involves understanding arthropod and plant ecology as much as the ecology of the study species to ensure appropriate sampling. We reiterate the importance of identifying the microhabitat in which a bird forages and its preferred arthropod prey to ensure that the sampling procedure is appropriate (Cooper and Whitmore 1990, Johnson 2000, Sherry et al. 2005), but we also suggest researchers understand arthropod-plant relationships to ensure that sampling techniques (e.g., mass versus area) truly account for sampling effort and address the question at hand.

\section{ACKNOWLEDGMENTS}

We thank numerous field assistants for their efforts, and T. Sherry, C. Conway, L. Powell and J. Quinn for comments and support. The Nebraska and Arizona Cooperative Fish and Wildlife Research Units are jointly supported by cooperative agreements of the U.S. Geological Survey, the U.S. Fish and Wildlife Service, and the Wildlife Management Institute with the Nebraska Game and Parks Commission and the Arizona Game and Fish Department, respectively. Any use of trade, firm, or product names is for descriptive purposes only and does not imply endorsement by the U.S. government. Financial support to Decker was provided by GK-12 Fellowship grant (DGE-0638744) from the National Science Foundation, T\&E Inc., the American Ornithologists' Union, Animal Behavior Society, Shikar Safari Club International Foundation, Arrington Memorial Scholarship, and the School of Natural Resources and the Environment at the University of Arizona. All methods were 
approved under permits from U. S. Fish and Wildlife Service (MB053041-2), U. S. Forest Service (Catalina National Forest, 2720), and Arizona Game and Fish Department (SP650825).

\section{LITERATURE CITED}

Andersson, M. 1981. On optimal predator search. Theor. Pop. Biol. 19:58-86; doi 10.1016/0040-5809(81)90035-6.

Bookhout, T. A. 1994. Research and Management Techniques for Wildlife and Habitats. Wildlife Soc., Bethesda, MD.

Cooper, R. J., and R. C. Whitmore. 1990. Arthropod sampling methods in ornithology. Studies Avian Biol. 13:29-37.

Cooperrider, A. Y., Boyd, R. J., and Stuart, H. R., eds. 1986. Inventory and Monitoring of Wildlife Habitat. U.S. Dept. Int., Bur. Land Mgmt. Service Center, Denver.

Decker, K. L., Conway, C. J., and Fontaine, J. J. 2012. Nest predation, food, and female age explain seasonal declines in clutch size. Evol. Ecol. 26:683-699; doi 10.1007/s10682-011-9521-7.

Field, C., and Mooney, H. A. 1983. Leaf age and seasonal effects on light, water, and nitrogen use efficiency in a California shrub. Oecologia 56:348-355; doi 10.1007/BF00379711.

Holmes, R. T., and J. C. Schultz. 1988. Food availability for forest birds: Effects of prey distribution and abundance on bird foraging. Can. J. Zool. 66:720-728; doi $10.1139 / z 88-107$.

Holmes, R. T., Schultz, J. C., and Nithnagle, P. 1979. Bird predation on forest insects: An exclosure experiment. Science 206:462-463; doi 10.1126/science.206.4417.462.

Johnson, M. D. 2000. Evaluation of an arthropod sampling technique for measuring food availability for forest insectivorous birds. J. Field Ornithol. 71:88-109; doi 10.1648/0273-8570-71.1.88.

Jorgensen, C. F., Stutzman, R. J., Anderson, L. C., Decker, S. E., Powell, L. A., Schacht, W. H., and Fontaine, J. J. 2013. Choosing a DIVA: A comparison of emerging digital imagery vegetation analysis techniques. Appl. Veg. Sci. 16:552-560; doi 10.1111/avsc. 12037.

Larcher, W. 2001. Physiological Plant Ecology, 4th ed. Springer-Verlag, New York.

Martin, T. E., and P. M. Barber. 1995. Red-faced Warbler (Cardellina rubrifrons), in The Birds of North America (A. Poole and F. Gill, eds.), no. 152. Acad. Nat. Sci., Philadelphia; doi 10.2173/bna.152.

McGrath, L. J., Van Riper, C., and Fontaine, J. J. 2009. Flower power: Tree flowering phenology as a settlement cue for migrating birds. J. Anim. Ecol. 78:22-30; doi 10.1111/j.1365-2656.2008.01464.x.

Meyer, E. G., and Davison, A. D. 1987. An electronic image plant growth measurement system. Trans. Am. Soc. Agric. Engineers 30:242-248; doi 10.13031/2013.30434.

Moir, M. L., Brennan, K. E. C., Majer, J. D., Fletcher, M. J., and Koch, J. M. 2005. Toward an optimal sampling protocol for Hemiptera on understory plants. J. Insect Cons. 9:3-20; doi 10.1007/s10841-004-2351-y.

Morris, R. F. 1960. Sampling insect populations. Annu. Rev. Entomol. 5:243-264; doi 10.1146/annurev.en.05.010160.001331.

Morrison, M. L., Ralph, C. J., Verner, J., and Jehl,, J. R. Jr. 1990. Avian foraging: Theory, methodology and applications. Studies Avian Biol. 13:1-471.

O'Neal, M. E., Landis, D. A., and Isaacs, R. 2002. An inexpensive, accurate method for measuring leaf area and defoliation through digital image analysis. J. Econ. Entomol. 95:1190-1194; doi 10.1603/0022-0493-95.6.1190. 


\section{A NONINVASIVE TECHNIQUE FOR SAMPLING FOOD AVAILABILITY}

Poulin, B., and Lefebvre, G. 1997. Estimation of arthropods available to birds: Effect of trapping technique, prey distribution, and bird diet. J. Field Ornithol. 68:426-442.

Sherry, T. W., Johnson, M. D., and Strong, A. M. 2005. Does winter food limit populations of migratory birds?, in Birds of Two Worlds: The Ecology and Evolution of Migration (R. Greenberg and P. P. Marra, eds.), pp. 414-425. Johns Hopkins Univ. Press, Baltimore.

Smith, K. G., and Rotenberry, J. T. 1990. Quantifying food resources in avian studies: Present problems and future needs. Studies Avian Biol. 13:3-5.

Southwood, T. R. E. 1980. Ecological Methods, with Special Reference to Insect Populations. Chapman and Hall, London.

Vitz, A. C., and Rodewald, A. D. 2006. Can regenerating clearcuts benefit matureforest songbirds? An examination of post-breeding ecology. Biol. Cons. 127:477-486; doi 10.1016/j.biocon.2005.09.011.

Accepted 23 April 2018 